\title{
Characterization of GABAergic Neurons in Cerebellar Primary Cultures and Selective Neurotoxic Effects of a Serum Fraction ${ }^{1}$
}

\author{
FRANCESCA ALOISI, ${ }^{2}$ M. TERESA CIOTTI, AND GIULIO LEVI ${ }^{3}$ \\ Istituto di Biologia Cellulare, Consiglio Nazionale delle Ricerche, Via Romagnosi 18/A, 00196 Roma, Italy
}

\begin{abstract}
The morphological and functional differentiation of GABAergic interneurons present in cerebellar primary cultures has been examined by means of $\left[{ }^{3} \mathrm{H}\right] \gamma$-aminobutyric acid (GABA) autoradiography and $\left[{ }^{3} \mathrm{H}\right] \mathrm{GABA}$ depolarizationevoked release. At 2 days in vitro these neurons showed scarce accumulation of radioactivity and no $\mathrm{Ca}^{2+}$-dependent $\mathrm{K}^{+}$-evoked or veratridine-induced release of $\left[{ }^{3} \mathrm{H}\right] \mathrm{GABA}$. At 5 days in vitro GABAergic interneurons appeared more intensely labeled and had grown out long and often branched neuritic processes; a large $\mathrm{Ca}^{2+}$-dependent release of $\left[{ }^{3} \mathrm{H}\right]$ GABA could be evoked by high $\mathrm{K}^{+}$. At later stages the progressive increase in labeling and branching of the neuritic processes was paralleled by a further increase in the amount and $\mathrm{Ca}^{2+}$ dependence of $\left[{ }^{3} \mathrm{H}\right] \mathrm{GABA}$ release; a tetrodotoxinsensitive, veratridine-stimulated release was also demonstrated. The $\left[{ }^{3} \mathrm{H}\right] \mathrm{GABA}$-accumulating stellate astrocytes present in the culture were not responsible for the observed release of the amino acid. GABAergic neurons were also identified by indirect immunofluorescence, using antibodies to the specific marker glutamic acid decarboxylase. Total renewal of the culture medium at 7 days in vitro caused a drastic $(90 \%)$ reduction in the number of GABAergic neurons and a concomitant decrease in the amount of $\left[{ }^{3} \mathrm{H}\right] \mathrm{GABA}$ uptake and release in the cultures. The disappearance of GABAergic neurons was caused by a low molecular weight $\left(M_{r}<1000\right)$ fraction of the serum used to supplement the basal culture medium. This serum component did not significantly influence the survival of the major neuronal population of the culture (the granule cells) and appeared to be selectively toxic for GABAergic neurons only after they had reached a quite advanced degree of morphological and functional differentiation in vitro. The toxic activity was no longer present in neuronal or glial conditioned media.
\end{abstract}

Received July 30, 1984; Revised January 10, 1985;

Accepted January 14, 1985

${ }^{1}$ We thank Dr. G. P. Wilkin tor a gift of anti-gilal fibrillary acidic protein antibody and Dr. V. Gallo for stimulating discussion. Antiserum to glutamic acid decarboxylase was a gift of the Laboratory of Clinical Science. National Institute of Mental Health, where it was developed under the supervision of Dr. I. J. Kopin, with Drs. W. Oertel, D. E. Schmechel, and M. Tappaz. This investigation was supported by North Atlantic Treaty Organization Research Grant $58 / 80$ and by a grant of the Italian National Research Council (Progetto Finalizzato M.P.R., SP3).

${ }^{2}$ To whom correspondence should be sent, at her present address: Istituto Superiore di Sanità, Viale R. Elena 299, 00161 Roma, Italy.

${ }^{3}$ Present address: Istituto Superiore di Sanità, Viale R. Elerra 299, 00161 Roma, Italy.
Primary cell cultures have become a powerful tool for studying the development of the functional properties of different neural cell types during their differentiation (Giacobini et al, 1980; Pfeiffer, 1982). Primary cultures, however, are generally heterogeneous; this is particularly true for neuron-enriched cultures, which often contain more than one neuronal cell type, in addition to a variable proportion of non-neuronal cells. In spite of this limitation, if the cellular composition of the cultures is well characterized, and if the functional parameters under study can be specifically related to a particular cell type, the behavior of a given cell population may be analyzed, even if this represents only a small fraction of the total cells present in the culture.

Among the best characterized neuron-enriched cultures are those derived from postnatal rat cerebella (Lasher, 1974; Messer, 1977; Currie and Dutton, 1980; Garthwaite and Balàzs, 1981; Levi and Ciotti, 1983). In these cultures, non-neuronal cells are very limited in number (<5\%; Levi et al., 1983; Thangnipon et al., 1983), and only two populations of neurons are present: the granule cells, which represent the large majority (about $98 \%$ in our culture conditions; Levi et al., 1984) and GABAergic interneurons, presumably stellate and basket cells (Currie and Dutton, 1980), which account for about $2 \%$ of the cells growing in the cultures (Levi and Ciotti, 1983; Levi et al., 1984)

Cultured GABAergic interneurons avidly take up exogenous $\left[{ }^{3} \mathrm{H}\right]$ $\gamma$-aminobutyric acid (GABA), and this property has been utilized to identify these neurons autoradiographically (Lasher, 1974; Burry and Lasher, 1978; Currie and Dutton, 1980; Levi and Ciotti, 1983). However, a subpopulation of cultured cerebellar astrocytes also accumulates $\left[{ }^{3} \mathrm{H}\right] \mathrm{GABA}$ with features similar to those of the neuronal uptake of the amino acid (Levi et al., 1983; Wilkin et al., 1983). Therelore, $\left[{ }^{3} \mathrm{H}\right]$ GABA auloradiography musl be combined with other cell identification criteria, such as immunocytochemical recognition of cell-specific antigens. Antibodies raised against glutamic acid decarboxylase (GAD), the biosynthetic enzyme for GABA, which have been amply utilized to map GABAergic neurons in situ (Ribak, 1978; Roberts, 1979; Wu, 1983), have óccasionally been used also to recognize these neurons in primary cultures. (Panula et al, 1981; Neale et al., 1983; Reisert et al., 1983). As to astroglial cells, they are generally identified using antibodies against glial fibrillary acidic protein (GFAP), the predominant component of the intermediate filaments of astrocytes (Bignami et al., 1980; Eng and De Armond, 1982).

One of the most specific properties of differentiated neurons is their ability to release the substance utilized as a neurotransmitter in response to depolarizing stimuli applied in the presence of $\mathrm{Ca}^{2+}$ (Llinas and Heuser, 1977). Calcium-dependent release of GABA has been demonstrated in primary cultures obtained from the cerebellum, as well as from other areas of the central nervous system (Farb et al., 1979; Snodgrass et al., 1980; Pearce et al., 1981; Schousboe et al., 1983).

As an extension of our previous investigations on the differentiation of neural cell types in cerebellar primary cultures (Gallo et al., 
1982; Levi et al., 1983, 1984; Wilkin et al., 1983), we have studied here the development of cultured cerebellar GABAergic interneurons. Due to their limited number in the cultures, their morphological differentiation could not be examined by phase-contrast observation and was monitored autoradiographically, whereas GAD and GFAP immunofluorescence techniques were applied to identify the $\left[{ }^{3} \mathrm{H}\right]$ GABA-accumulating cell types. The functional maturation of GABAergic neurons was analyzed by studying the development of their ability to release $\left[{ }^{3} \mathrm{H}\right] \mathrm{GABA}$ in a way compatible with a neurosecre tory process. In the course of this study we have also observed that, in our culture system, the survival of differentiated GABAergic neurons, but not that of granule neurons, is severely affected by a low molecular weight component present in the serum used to supplement the basal culture medium.

\section{Materials and Methods}

Culture conditions. Neuron-enriched primary cultures from 8-day-old Wistar rat cerebella were prepared and maintained as previously described (Lev et al., 1984). Cells were seeded $\left(2.5 \times 10^{6} \mathrm{cells} /\right.$ dish $)$ on poly-L-lysine-coated $35-\mathrm{mm}$ Nunc plastic dishes containing, for the autoradiography and immunofluorescence experiments, four $113-\mathrm{mm}^{2}$ round glass coverslips. The culture medium consisted of Eagle's hasal medium (RME), supplemented with $25 \mathrm{mM} \mathrm{KCl}, 2 \mathrm{mM}$ glutamine, $0.1 \mathrm{mg} / \mathrm{ml}$ of gentamycin, and $10 \%$ heatinactivated fetal calf serum from different sources (Grand Island Biological Co., (GIBCO), Flow Laboratories, and Hazleton). The antimitotic cytosine arabinoside $(10 \mu \mathrm{M})$ was added $20 \mathrm{hr}$ after plating to prevent proliferation of non-neuronal cells. The culture medium was replaced with fresh, complete medium 2 days after plating; subsequent medium changes were performed as described under "Results." The conditioned media were obtained from primary astrocyte-enriched (Wilkin et al., 1983) or neuron-enriched cerebellar cultures. The conditioning time was 5 days, from 7 to 12 days in vitro (DIV). After collection, the glial conditioned medium was supplemented with $\mathrm{KCl}$ to give a concentration of $25 \mathrm{~mm}$.

Autoradiography. Cultures at 2, 5, 8, and 12 DIV were incubated for 30 $\mathrm{min}$ at $37^{\circ} \mathrm{C}$ in $1 \mathrm{ml}$ of Krebs-Ringer medium (128 mM NaCl, $5 \mathrm{~mm} \mathrm{KCl}, 2.7$ $\mathrm{mm} \mathrm{CaCl}, 1.2 \mathrm{~mm} \mathrm{MgSO}, 1 \mathrm{~mm} \mathrm{Na} \mathrm{HPO}_{4}, 10 \mathrm{~mm}$ glucose, and $20 \mathrm{~mm}$ HEPES at $\mathrm{pH} 7.35$ ); $\left[{ }^{3} \mathrm{H}\right] \mathrm{GABA}$ ( 2 to $3 \mu \mathrm{Ci} / \mathrm{ml}$, specific activity, $37 \mathrm{Ci} / \mathrm{mmol}$; New England Nuclear Corp.) was added to the same medium for another 10 min. Incubation was ended by three Krebs-Ringer washes, and the cells were fixed for $1 \mathrm{hr}$ at $25^{\circ} \mathrm{C}$ with $3.5 \%$ glutaraldehyde in $0.1 \mathrm{~m}$ phosphate buffer at $\mathrm{pH} 7.35$, air dried, glued to glass slides, coated with llford $\mathrm{K} 2$ emulsion $\left(1: 2.5\right.$ in $\left.\mathrm{H}_{2} \mathrm{O}, \mathrm{V} / \mathrm{V}\right)$, and exposed for 14 days at $4^{\circ} \mathrm{C}$ prior to development with Kodak Dektol. The cells were stained with Mayer's hemalum followed by $0.1 \%$ eosin.

Immunofluorescence. GAD-containing cells were visualized by indirect immunofluorescence following previously described procedures (Tappaz et al., 1981), with slight modifications. The cells were fixed with $4 \%$ paraformaldehyde in phosphate-buffered saline (PBS) for $30 \mathrm{~min}$, washed three times with PBS, treated with Tris- $\mathrm{HCl}(0.1 \mathrm{M}, \mathrm{pH} 7.3)$ containing $0.25 \%$ Triton X100 for $15 \mathrm{~min}$, and washed in Tris- $\mathrm{HCl}$. The coverslips were then incubated with sheep anti-GAD serum (1:1000 in PBS) for $18 \mathrm{hr}$ at $4^{\circ} \mathrm{C}$, washed with PBS, and incubated for $30 \mathrm{~min}$ at $25^{\circ} \mathrm{C}$ with fluorescein-conjugated rabbit anti-sheep antibodies (1:10 in PBS) Wellcome (Laboratories). Coverslips were mounted in glycerol:PBS and examined with a Leitz Dialux 20 EB fluorescence microscope. In some experiments colchicine $(1 \mu \mathrm{M})$ was added to the cultures $24 \mathrm{hr}$ before fixation. Control experiments with preimmune sheep sera did not show any specific fluorescence.

Combined $\left.{ }^{3} H\right] G A B A$ autoradiography and GFAP immunofluorescence. Following [ $\left.{ }^{3} \mathrm{H}\right] \mathrm{GABA}$ incubation (as described above), cultures were fixed with $2.5 \%$ glutaraldehyde in PBS for $15 \mathrm{~min}$, washed in PBS, permeabilized with methanol for $15 \mathrm{~min}$ at $-20^{\circ} \mathrm{C}$, and then rinsed three times for $4 \mathrm{~min}$ with $\mathrm{NaBH}_{4}(1 \mathrm{mg} / \mathrm{ml})$ and washed in PBS. The coverslips were then incubated at room temperature for 30 min with rabbit anti-GFAP serum (diluted 1:20 in PBS), washed in PBS, incubated with anti-rabbit rhodamineconjugated antiserum (Nordic Immunology) diluted 1:50 in PBS, washed again, and then coated with llford $\mathrm{K} 2$ emulsion $\left(1: 2.5\right.$ in $\left.\mathrm{H}_{2} \mathrm{O}, \mathrm{v} / \mathrm{V}\right)$ and developed after exposise for 24 to $48 \mathrm{hr}$.

Release and uptake experiments. Culture dishes at the selected stages in vitro were washed twice with prewarmed Krebs-Ringer medium containing $10 \mu \mathrm{M}$ amino-oxyacetic acid, to provent GABA catabolism, and then incubated in $1 \mathrm{ml}$ of the same medium for $30 \mathrm{~min}$ at $37^{\circ} \mathrm{C}$; at this time $\left[{ }^{3} \mathrm{H}\right] \mathrm{GABA}$ $(0.5 \mu \mathrm{Ci} / \mathrm{ml})$ was added and the incubation was continued for $10 \mathrm{~min}$. Then the dishes were transferred to a rulaling warm $\left(37^{\circ} \mathrm{C}\right)$ plate and washed three times with $2 \mathrm{ml}$ of medium for a period of $10 \mathrm{~min}$. Release of $\left[{ }^{3} \mathrm{H}\right] \mathrm{GABA}$ was monitored from this time, by incubating the cultures in $1 \mathrm{ml}$ of medium which was renewed every $5 \mathrm{~min}$ for a period of $25 \mathrm{~min}$, and was collected for counting. Depolarizing media (containing either $50 \mathrm{mM} \mathrm{KCl}$-replacing an equimolar amount of $\mathrm{NaCl}$-or $50 \mu \mathrm{M}$ veratridine) were applied at the fourth medium change; calcium-free or tetrodotoxin-containing media were applied starting from the second and third medium change, respectively. Calciumfree media were used without the addition of chelating agents such as EGTA, because calcium removal was sufficient to abolish almost completely the depolarization-evoked release of $\left[{ }^{3} \mathrm{H}\right] \mathrm{GABA}$. Moreover, EGTA tended to cause cell detachment from the dishes. At the end of the experiments, aliquots of the collected media and perchloric acid extracts of the cells were counted for radioactivity. Estimates of $\left[{ }^{3} \mathrm{H}\right] \mathrm{GABA}$ uptake were obtained indirectly from the release experiments, by summing the radioactivity released to that remaining in the cells at the end of the release phase.

Uitrafiltration of the serum. The serum (GIBCO) used to supplement the basal culture medium was applied to an Amicon PM 10 ultrafiltration membrane having a molecular weight cutoff of 10,000 daltons. The fractions retained by the filter ( $R 10$ ). which were concentrated 10 times, were diluted in $\mathrm{H}_{2} \mathrm{O}$ and fittered again, the second filtrate was discarded. Part of the first filtrate ( $F 10)$ was applied to a YM 2 membrane (molecular weight cutoff of 1,000 daltons), and the corresponding fractions ( $R 2$ and $F 2$ ) were collected. The various serum fractions were diluted at the appropriate concentration with BME. The media containing the different fractions of the serum were used to renew the culture medium at 7 DIV.

\section{Results}

Autoradiographic examination of rat cerebellar interneuron-enriched cultures incubated in the presence of $0.05 \mu \mathrm{M}\left[{ }^{3} \mathrm{H}\right] \mathrm{GABA}$ showed that silver grains were distributed over two cell types: a subpopulation of astrocytes, exhibiting a stellate morphology (Levi et al., 1983), and a small subset of neurons, which could be distinguished from granule cells for their larger perikarya and different morphology (Fig. 1). In early cultures (2 DIV) most of the accumulation of $\left[{ }^{3} \mathrm{H}\right] \mathrm{GABA}$ was confined to astrocytes; $\left[{ }^{3} \mathrm{H}\right] \mathrm{GABA}$-accumulating neurons, generally exhibiting a bipolar aspect, were labeled only lightly over their cytoplasm and their relatively short processes (Fig. 1A). In 5-day cultures, GABAergic neurons appeared quite intensely labeled over their perikarya and the often long processes emerging from them. At this stage some cells maintained a bipolar aspect, whereas others showed only one branched axonal process (Fig. $1 B$ ). At subsequent stages ( 8 and 12 DIV) the neuritic processes, which showed characteristic bead-like structures along them, elongated further and formed an intricate network (Fig. 1F). Although at this stage it was often difficult to assess the morphology of individual neurons, the majority of the labeled neuronal cells appeared to possess only one branched process; bipolar and, more rarely, multipolar neurons were also present. Some examples of labeled GABAergic neurons with different morphologies are given in Figure $1, C$ to $E$.

GABAergic neurons were also detected by visualization of GAD by indirect immunofluorescence. Under standard conditions, the fluorescent staining procedure evidenced much more clearly the neuronal processes than the cell bodies from which they emerged (Fig. 2A). The processes were highly branched and were characterized by the presence of numerous varicosities along them. The cell bodies, however, could be better visualized if colchicine (a blocker of the axonal transport) was added to the culture medium (Ribak et al., 1978) $24 \mathrm{hr}$ before processing for the immunofluorescence staining (Fig. 2B).

To make certain that the large stellate cells accumulating $\left[{ }^{3} \mathrm{H}\right]$ GABA (Fig. 1, B and $F$; see also Levi et al., 1983) were indeed astrocytes and not neurons, a double-labeling technique was utilized, for the simultaneous visualization of the astrocyte-specific marker GFAP by indirect immunofluorescence and of $\left[{ }^{3} \mathrm{H}\right] \mathrm{GABA}$ uptake by autoradiography. Coexistence of the two labels was demonstrated in the large stellate cells identified as astrocytes on the basis of their morphology (Fig. 3). It has to be added that GAD-positive stellate cells were never seen.

Neurons labeled by $\left[{ }^{3} \mathrm{H}\right] \mathrm{GABA}$ made up about $2 \%$ of the total cells present in the culture at 5 DIV (Levi and Ciotti, 1983). This 

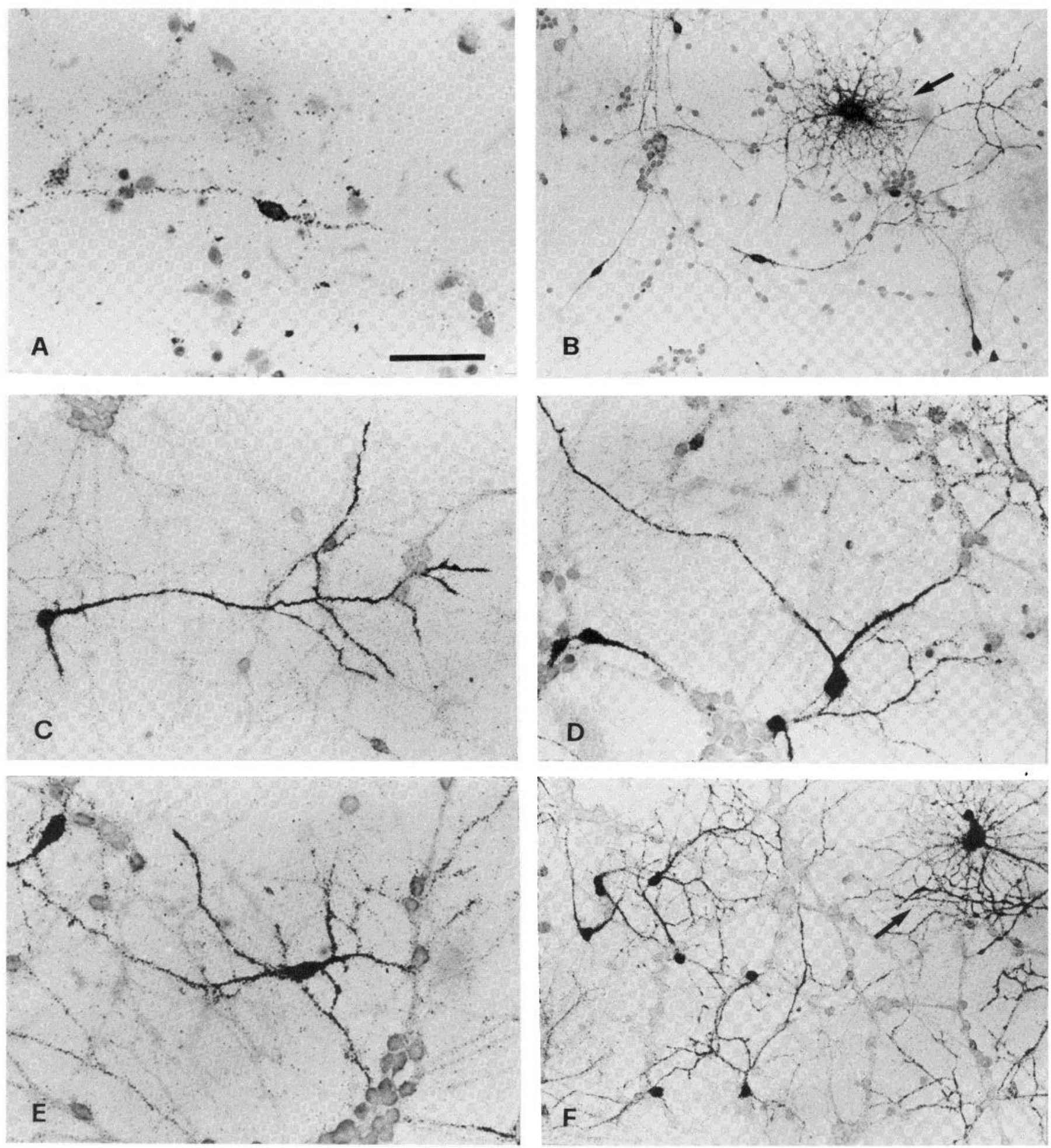

Figure 1. Light microscopic autoradiographs of neuron-enriched cerebellar cultures following incubation with $0.05 \mu \mathrm{M}\left[{ }^{3} \mathrm{H}\right] \mathrm{GABA}$ at different stages in vitro. A, A 2-day culture showing a lightly labeled GABAergic neuron with a bipolar morphology. B, A 5-day culture showing heavily labeled GABAergic neurons, some with a bipolar morphology and others with a unipolar and branched neuritic process; a large stellate astrocyte (arrow) heavily labeled by [ ${ }^{3} \mathrm{H}$ ] GABA is also shown, but the granule cells appear very scarcely or not at all labeled. $C$ to $E$, Eight-day cultures showing heavily labeled GABAergic neurons with a monopolar, bipolar, and multipolar morphology, respectively. $F, A$ 12-day culture showing very intensely labeled GABAergic neurons with processes that form an intricate network, and a stellate astrocyte (arrow). Scale bar $=35 \mu \mathrm{m}(A) ; 100 \mu \mathrm{m}(B$ and $F) ; 55 \mu \mathrm{m}(C$ and $D) ; 45 \mu \mathrm{m}(E)$.

proportion was maintained unchanged in cultures up to 12 DIV, if the culture medium was either never changed, or renewed at 2 DIV as in our standard conditions.

When cerebellar cultures at different developmental stages were tested for their ability to release preaccumulated $\left[{ }^{3} \mathrm{H}\right] \mathrm{GABA}$ in re- sponse to a depolarizing concentration of $\mathrm{KCl}$, the period between 2 and 5 DIV appeared to be a critical one for the development of the features of a neurosecretory process. Whereas at $2 \mathrm{DIV} \mathrm{no} \mathrm{Ca}^{2+}$. dependent release of the amino acid could be evoked by $50 \mathrm{~mm}$ $\mathrm{KCl}$, at $5 \mathrm{DIV}$ the $\mathrm{Ca}^{2+}$ dependence of the stimulus-coupled release 

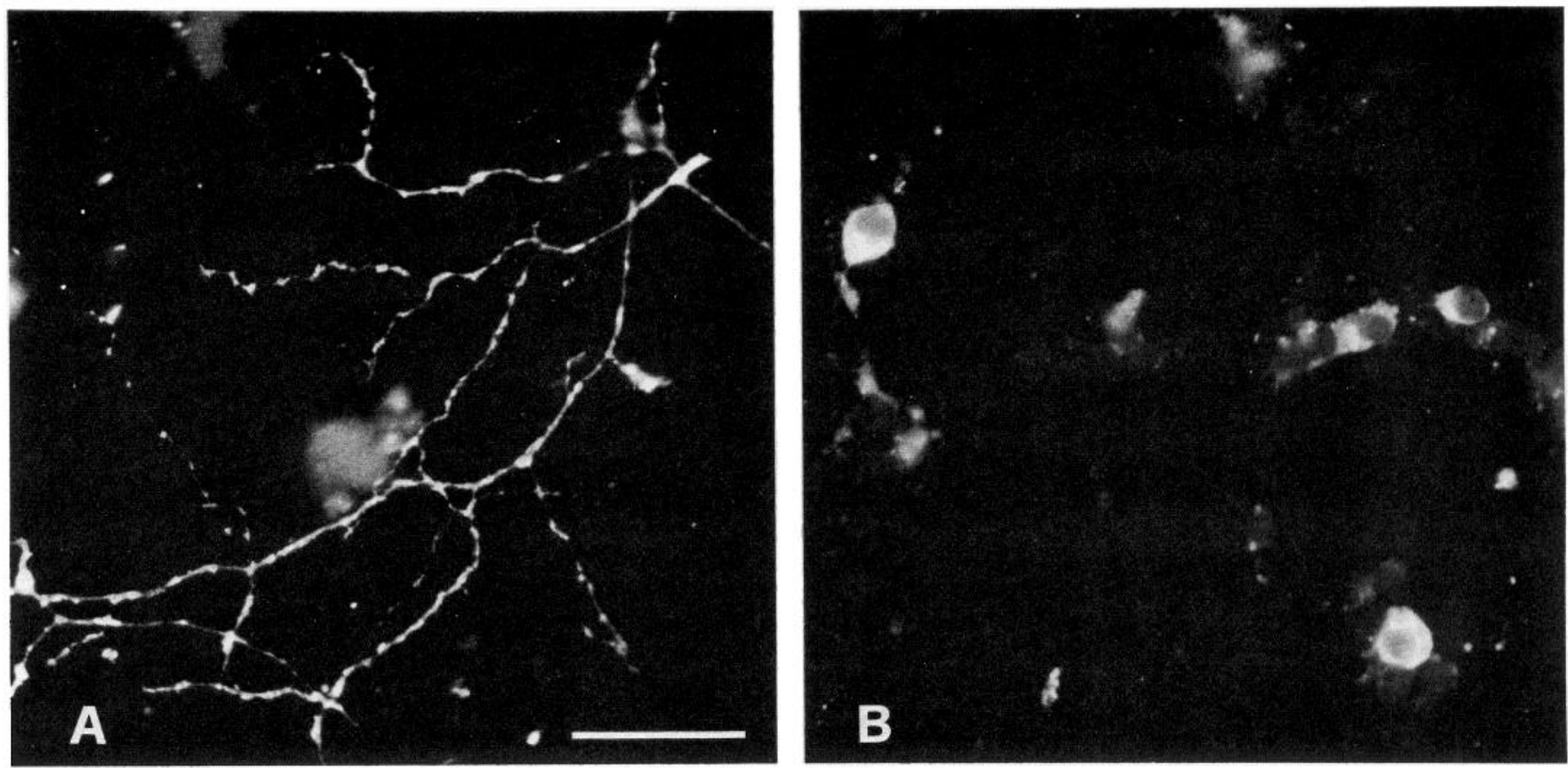

Figure 2. Indirect immunofluorescence labeling of GABAergic neurons in 12-day cerebellar cultures using sheep GAD antiserum and fluorescein conjugated anti-sheep immunoglobulin. $A$, Intensely fluorescent neuritic process showing characteristic varicosities along its branches. $B$, GAD-positive neuronal perikarya in cultures treated for $24 \mathrm{hr}$ with $1 \mu \mathrm{M}$ colchicine; using this procedure the neuritic processes are partly disrupted and scarcely or not at all stained. Scale bar $=50 \mu \mathrm{m}$.
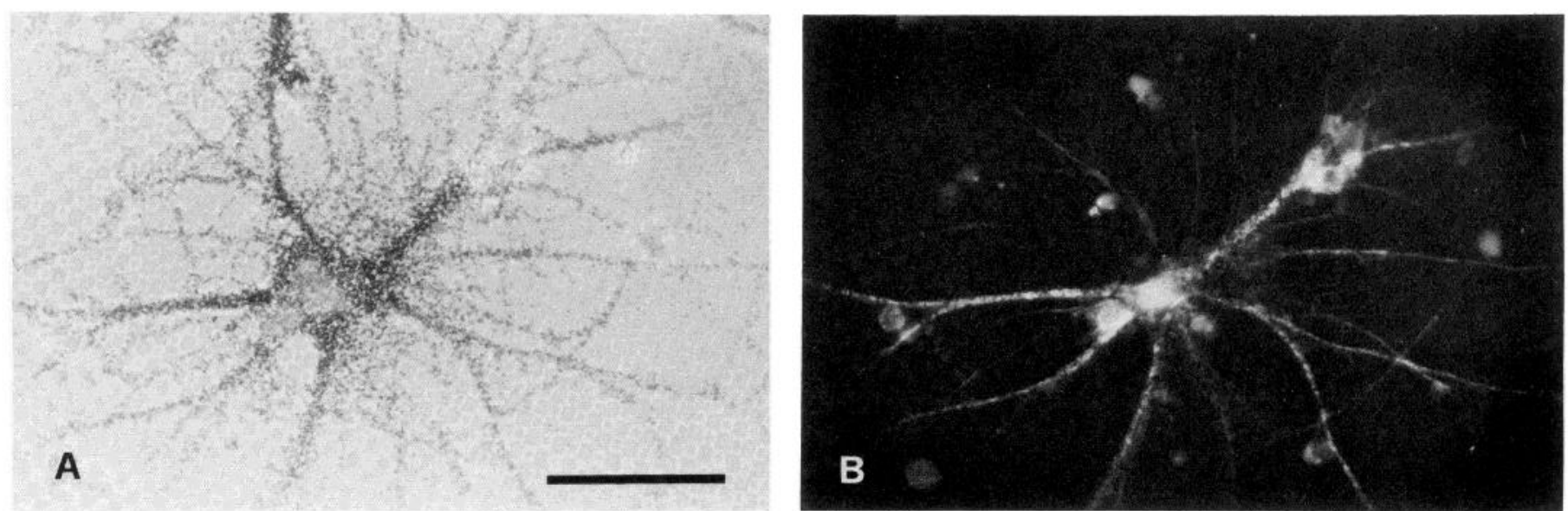

Figure 3. Identification of astrocytes present in cerebellar neuron-enriched cultures (12 DIV) by combined $\left[{ }^{3} \mathrm{H}\right] \mathrm{GABA}$ autoradiography $(A)$ and anti-GFAP immunofluorescence $(B)$. Cultures were first incubated in the presence of $0.1 \mu \mathrm{M}\left[{ }^{3} \mathrm{H}\right] \mathrm{GABA}$, fixed, and subsequently incubated with rabbit anti-GFAP and anti-rabbit rhodamine-conjugated antibodies. $A$, Phase contrast micrographs of a single stellate cell labeled by [ $\left.{ }^{3} \mathrm{H}\right] \mathrm{GABA}$. $B$, View of the same field under rhodamine optics showing GFAP positivity of the $\left[{ }^{3} \mathrm{H}\right]$ GABA-labeled cell. Cell bar $=40 \mu \mathrm{m}$.

was already about $70 \%$ of that observed at 12 DIV (Fig. 4, left). The percentage increase of the evoked release over the basal efflux was $300 \%$ at 5 and 8 DIV , and $400 \%$ at 12 DIV. The development of $\left[{ }^{3} \mathrm{H}\right] \mathrm{GABA}$-evoked release was also studied using the alkaloid veratridine as the depolarizing agent. Figure 4 (right) shows that veratridine $(50 \mu \mathrm{M})$ caused only a minimal increase of $\left[{ }^{3} \mathrm{H}\right] \mathrm{GABA}$ release in cultures at 2 DIV, whereas at 8 DIV the release of the radioactive amino acid was greatly enhanced. The effect of the alkaloid was completely antagonized by the $\mathrm{Na}^{+}$channel blocker tetrodotoxin $(0.5 \mu \mathrm{M})$.

In order to identify which cell type in the culture was responsible for the observed amino acid release, we examined autoradiographically the distribution of radioactivity in 8-DIV cultures that had been preincubated in the presence of $\left[{ }^{3} \mathrm{H}\right] \mathrm{GABA}$ and then depolarized three consecutive times with $50 \mathrm{mM} \mathrm{KCl}$ in the presence of $\mathrm{Ca}^{2+}$ ions. This procedure had been utilized previously to study the sites from which newly synthesized $\left[{ }^{3} \mathrm{H}\right]$ glutamate is released in cerebellar neuronal cultures (Levi et al., 1984). A selective depletion of silver grains could be detected over the distal part of the axonal processes of GABAergic neurons (Fig. 5B), whereas the intensity of labeling of the stellate astrocytes did not appear to be reduced, when compared to that of the nondepolarized controls (Fig. 5A).

A renewal of the culture medium (BME supplemented with fetal calf serum) at 7 DIV (in addition to that routinely performed at 2 DIV) caused a drastic $(90 \%)$ reduction in the number of labeled GABAergic neurons present in the culture at 8 DIV or at subsequent stages (Table I). The data of Table I refer to observations made over a period of about 2 years, using several batches of BME (GIBCO) and fetal calf serum (GIBCO). More recently, we tested also the fetal calf sera from two other producers (Flow Laboratories and Hazleton), and we obtained similar results. Other experiments (see following 


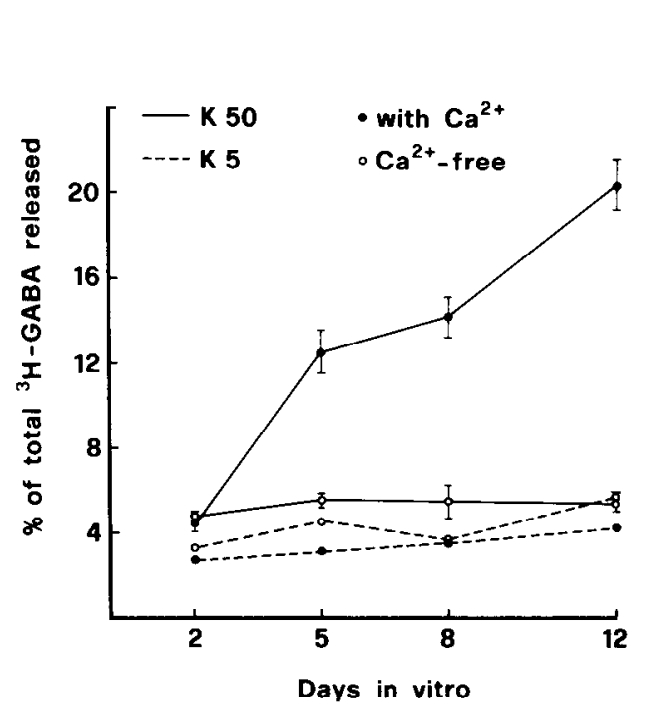

text) excluded the hypothesis that the BME could be responsible for the adverse effects of the medium change on GABAergic neurons.

Loss of GABAergic neurons was also documented using the GAD immunofluorescence technique. In cultures that had received a medium change at $7 \mathrm{DIV}$, the fluorescent cells almost disappeared. Counting fluorescent cells was difficult, unless the cultures were treated with colchicine to better visualize the cell bodies (see above). In one experiment we adopted this procedure and found that a medium change at day 7 reduced by about $80 \%$ the number of GAD-positive cells detectable in cultures at 13 DIV. This finding excluded the possibility that the loss of GABAergic neurons evidenced autoradiographically could be due to the fact that the neurons had lost their ability to accumulate the radioactive amino acid.

In agreement with the loss of GABAergic neurons described above, cultures subjected to a medium change at 7 DIV showed a decreased accumulation of $\left[{ }^{3} \mathrm{H}\right] \mathrm{GABA}$ and became unable to release preaccumulated $\left[{ }^{3} \mathrm{H}\right] \mathrm{GABA}$ in response to depolarizing stimuli, when tested at 8 DN or at subsequent stages (Table I). If the culture medium was renewed at an earlier stage ( 5 rather than 7 DIV), the values of $\left[{ }^{3} \mathrm{H}\right] \mathrm{GABA}$ uptake and evoked release were only slightly reduced (Table I). In one experiment run in triplicate, we observed that renewal of the medium at 8 or 9 DIV, rather than at 7 DIV, appeared to be as effective in causing death of GABAergic neurons. Moreover, omitting the medium change at 2 DIV did not prevent the loss of $\left[{ }^{3} \mathrm{H}\right] \mathrm{GABA}$ uptake and evoked release caused by the medium renewal at 7 DIV (data not presented).

Observation of live cultures at phase contrast did not reveal any apparent difference in the density and distribution of the neuronal aggregates and of the fasciculated fibers, whether or not the culture medium was changed at day 7 . Since granule cells account for greater than $95 \%$ of the cell population in these cultures, these neurons appeared to be less or not affected by the medium change. In agreement with this view, the uptake and the depolarizationinduced release of the glutamate analogue $\left[{ }^{3} \mathrm{H}\right]$-D-aspartate (Levi et al., 1984) were only modestly reduced in 8-DIV cultures subjected to a medium renewal at day 7 (the percentage reduction of uptake was $8 \pm 5$; that of evoked rolcasc was $22 \pm 13$ in three experiments run in duplicate). Astroglial cells labeled by $\left[{ }^{3} \mathrm{H}\right] \mathrm{GABA}$, instead, showed some sensitivity to the 7-DIV medium change, as their number was $53 \pm 8 \%$ reduced (mean \pm SEM of four duplicate experiments) when assessed in autoradiograms of 8-day cultures.

in order to exclude the possibility that a mechanical factor could be responsible for the observed loss of GABAergic neurons, 7-day
Figure 4. Development of depolarizationinduced release of $\left[{ }^{3} \mathrm{H}\right] \mathrm{GABA}$ in cerebellar primary cultures. Left, Cultures at 2, 5, 8, and 12 DIV were incubated for $10 \mathrm{~min}$ in the presence of $0.5 \mu \mathrm{Ci} / \mathrm{ml}$ of $\left[{ }^{3} \mathrm{H}\right] \mathrm{GABA}$ and $10 \mu \mathrm{M}$ aminooxyacetic acid, and then subjected to 5 -min washes with $1 \mathrm{ml}$ of medium. During the first $15 \mathrm{~min}$ of the release phase a steady basal level of $\left[{ }^{3} \mathrm{H}\right] \mathrm{GABA}$ release was achieved; a depolarizing medium containing $50 \mathrm{~mm} \mathrm{KCl}$ was added at the fourth wash. Half of the culture dishes were treated with $\mathrm{Ca}^{2+}$-free media starting from the second wash. Right, Cultures at 2 and 8 DIV were incubated with $\left[{ }^{3} H\right]$ GABA and washed as described above, except that $50 \mu \mathrm{M}$ veratridine was present in the medium of the fourth wash; half of the dishes depolarized with veratridine were treated with $0.5 \mu \mathrm{M}$ tetrodotoxin $(T T X)$ in the third and fourth washes. The radioactivity released in the prestimulation and stimulation washes is expressed as percentage of the total radioactivity recovered in the washes plus that remaining in the cells at the end of the release phase. Each point is the average of four to five duplicate experiments \pm SEM. cultures were subjected to a medium change with a conditioned medium taken from parallel culture dishes. In this condition GABAergic neuron survival was unaffected. Similarly, when the cultures were subjected to a medium change at 7 DIV with glial conditioned media obtained from confluent astrocyte cultures, autoradiographic cell counts and values of $\left[{ }^{3} \mathrm{H}\right] \mathrm{GABA}$ uptake and evoked release were identical to those of control cultures (Table I). Cultures grown from the time of plating in glial conditioned medium did not show any difference in GABAergic cell survival when compared to those grown in standard medium (data not shown). In contrast, a serumcontaining medium kept in the incubator at $37^{\circ} \mathrm{C}$ for 5 days in the absence of cells maintained its toxic activity toward GABAergic neurons, as shown by the loss of $\left[{ }^{3} \mathrm{H}\right] \mathrm{GABA}$ uptake and evoked release (Table I).

In a subsequent series of experiments, the fetal calf serum (GIBCO) used to supplement the BME was processed through an Amicon PM 10 ultrafiltration membrane having a molecular weight cutoff of 10,000 daltons, and the retained $(R 10)$ and filtrate $(F 10)$ fractions were collected. At 7 DIV some cultures were subjected to a medium change with BME supplemented with the $R 10$ fraction alone, whereas other cultures received, in addition, the $F 10$ fraction. Control cultures were not subjected to a medium change at 7 DIV. At 8 DIV all of the cultures were tested for their ability to accumulate $\left[{ }^{3} \mathrm{H}\right] \mathrm{GABA}$ and to release it in depolarizing conditions. One autoradiographic experiment for cell counts was also performed. In cultures which had received only the $R 10$ fraction, all of the values considered were similar to those of control cultures; in contrast, the cultures exposed also to the $F 10$ fraction showed a marked decrease in GABAergic neuron counts and in $\left[{ }^{3} \mathrm{H}\right] \mathrm{GABA}$ release and uptake (Table II). When the $F 10$ fractions were further processed through a YM 2 membrane, with molecular weight cutoff of 1,000 daltons, almost all of the neurotoxic activity was recovered in the filtrate ( $F$ 2) fraction (Table $I$ ). In fact, cultures which received the retained fractions from the two ultrafiltration procedures, $\mathrm{R} 10$ and $\mathrm{R} 2\left(M_{r}>\right.$ $1,000)$, with the medium change at 7 DIV showed only a small decrease in GABAergic neuron survival, whereas [ $\left.{ }^{3} \mathrm{H}\right] \mathrm{GABA}$ uptake and release values were markedly decreased in cultures exposed to $R 10$ plus $F 2$ fractions (Table II).

\section{Discussion}

In the first part of this paper we have characterized some of the properties of GABAergic neurons growing in granule cell-enriched primary cultures from postnatal rat cerebella. GABAergic neurons accounted for only $2 \%$ of the total cell population (Levi and Ciotti, 1983) and were identified by $\left[{ }^{3} \mathrm{H}\right]$ GABA autoradiography (Fig. 1) and 

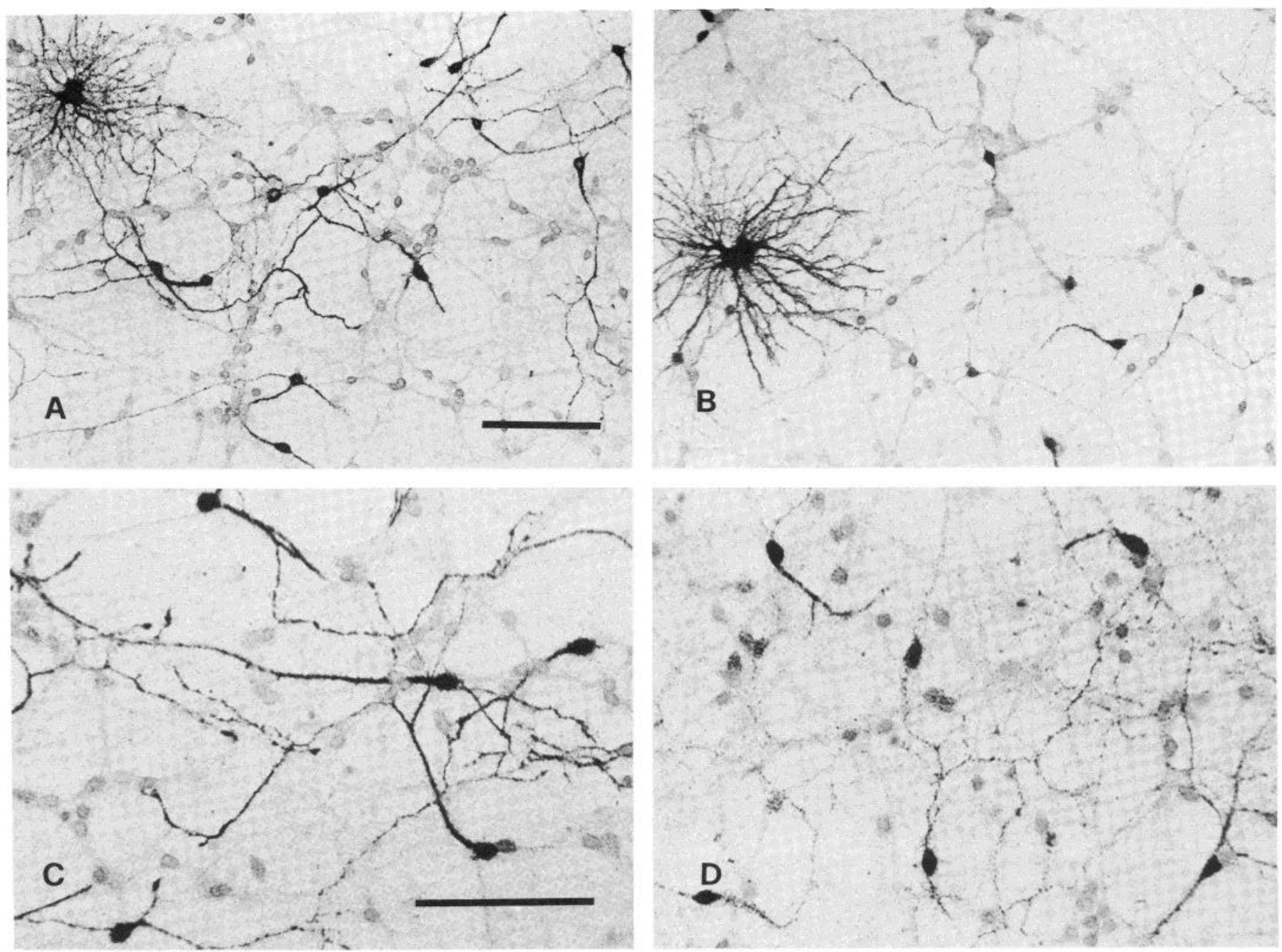

Figure 5. Autoradiographs showing the depletion of preaccumulated $\left[{ }^{3} \mathrm{H}\right] \mathrm{GABA}$ in 8 -day cultures following exposure to a depolarizing stimulus. Cultures were incubated in the presence of $0.1 \mu \mathrm{M}\left[{ }^{3} \mathrm{H}\right] \mathrm{GABA}$ and $10 \mu \mathrm{M}$ amino-oxyacetic acid. The cultures in $B$ and $D$ were then depolarized three times for 5 min at 10-min intervals with $50 \mathrm{~mm} \mathrm{KCl}$; the control cultures in $A$ and $C$ were washed during the same period with a nondepolarizing medium. Only the neuronal cells and, in particular, the distal parts of the neuritic processes are depleted of radioactivity in $B$ and $D$; the stellate astrocyte (see $B$ ) remains intensely labeled. Data similar to those shown were consistently reproduced in three different experiments run in duplicate. Scale bars $=100 \mu \mathrm{m}$; the magnification was the same in $A$ and $B$, and in $C$ and $D$, respectively.

by indirect immunofluorescence, using anti-GAD antibodies (Fig. 2). The development of the functional activity of these neurons was monitored by studying their ability to release preaccumulated $\left[{ }^{3} \mathrm{H}\right]$ GABA in response to depolarizing stimuli (Fig. 4). The autoradiography and the release experiments, performed with cultures grown for 2 to 12 DIV, revealed that GABAergic neurons progressively acquire the ability to accumulate $\left[{ }^{3} \mathrm{H}\right] \mathrm{GABA}$ and, in agreement with previous results (Pearce et al., 1983), to release it with the features $\left(\mathrm{Ca}^{2+}\right.$ dependence and veratridine sensitivity) of a neurotransmitter release process; they also showed that these properties develop concomitantly with the morphological differentiation (neurite elongation and arborization) of GABAergic neurons. The functional maturation of cerebellar GABAergic neurons in culture seems to proceed somewhat faster than that of granule neurons, as assessed in previous investigations (Gallo et al., 1982; Levi et al., 1984).

The fact that in the present study it was possible to demonstrate the maturation of a neurosecretory process for $\left[{ }^{3} \mathrm{H}\right] \mathrm{GABA}$, even if the competent neuronal population represents only a minor fraction $(2 \%)$ of the cultured cells, confirms the great specificity of the neurotransmitter uptake and release processes and documents that this specificity is maintained in cultured neurons.

The validity of $\left[{ }^{3} \mathrm{H}\right] \mathrm{GABA}$ autoradiography for the visualization of cultured GABAergic neurons was corroborated by GAD immunofluorescence data. In fact, the number and the morphology of the GAD-positive cells were similar to those of GABAergic neurons identified by autoradiography. Since we did not perform double-label experiments $\left(\left[{ }^{3} \mathrm{H}\right] \mathrm{GABA}\right.$ autoradiography and GAD immunofluorescence), the possibility that not all of the GAD-positive cells are capable of $\left[{ }^{3} \mathrm{H}\right] \mathrm{GABA}$ uptake, and vice versa, cannot be ruled out at present. In previous studies on different culture systems, coexistence of $\left[{ }^{3} \mathrm{H}\right] \mathrm{GABA}$ autoradiographic uptake and GAD immunoreactivity was found to be present in most of the labeled neurons (Neale et al., 1983; Reisert et al., 1983).

Autoradiographic accumulation of $\left[{ }^{3} \mathrm{H}\right] \mathrm{GABA}$ was also observed over some large stellate cells (Fig. 1, B and F) identifiable as astrocytes (Levi et al., 1983; Wilkin et al., 1983). These cells were always GAD negative (data not shown) and GFAP positive (Fig. 3). Previous studies (Levi et al., 1983) had shown that the number of stellate astrocytes present in neuron-enriched cerebellar primary cultures drastically decreased from 2 to 12 DIV. This observation, together with the present data on the progressive increase in the $\mathrm{Ca}^{2+}$-dependent $\left[{ }^{3} \mathrm{H}\right] \mathrm{GABA}$-evoked release, supports the view that GABAergic neurons were the main population from which the radioactive amino acid was released with the features of a neurosecretory 


\section{TABLE I}

Effects of medium changes on GABAergic neuron survival in cerebellar primary cultures

Cells were grown in BME supplemented with 10\% felal call serum (GIBCO). Some cultures (controls) were subjected to a medium change with fresh medium at 2 DIV; parallel cultures were subjected, in addition, to a medium change with tresh medium at 5 or at 7 DIV, or to a medium change at 7 DIV with glial conditioned medium or with a medium kept in the incubator in the absence of cells (acellular). GABAergic neuron survival was tested at 8 DIV by assessing: (a) $\mathrm{K}^{+}$-evoked release of $\left.{ }^{3} \mathrm{H}\right] \mathrm{GABA}$ (peak release minus basal release; see Fig. 4 legend); (b) $\left.{ }^{3} \mathrm{H}\right] \mathrm{GABA}$ uptake (see "Materials and Methods"). (c) counts of [ $\left.{ }^{3} \mathrm{H}\right] \mathrm{GABA}$-labeled neurons: 40 fields/coverslip were counted, each field representing an area of $0.24 \mathrm{~mm}^{2}$. A mean of $3490 \pm$ 208 GABAergic neurons/coverslip was obtained in control cultures. All of the data presented in this table are expressed as percentage of the values obtained in control cultures.

\begin{tabular}{lccc}
\hline \multirow{2}{*}{ Medium Change } & \multicolumn{3}{c}{ Percentage of Control } \\
\cline { 2 - 4 } & $\begin{array}{c}\text { [ }^{3} \mathrm{H} \text { ]GABA } \\
\text { Release }\end{array}$ & $\begin{array}{c}{ }^{3} \mathrm{H} \text { HGABA } \\
\text { Uptake }\end{array}$ & $\begin{array}{c}\text { GABAergic } \\
\text { Cell Counts }\end{array}$ \\
\hline Fresh medium, 2 DIV & $100(6)^{a}$ & $100(6)$ & $100(3)$ \\
Fresh medium, 5 DN & $72 \pm 8^{5}(3)$ & $85 \pm 9(3)$ & $\mathrm{NT}^{\circ}$ \\
$\begin{array}{c}\text { Fresh medium, 7 DN } \\
\text { Glial conditioned me- }\end{array}$ & $6 \pm 5(6)$ & $33 \pm 4(6)$ & $9 \pm 1(3)$ \\
$\quad \begin{array}{l}\text { dium, 7 DIV } \\
\text { Incubated acellular me- }\end{array}$ \\
$\quad$ dium, 7 DIV
\end{tabular}

${ }^{a}$ Numbers in parentheses, number of duplicate experiments.

${ }^{D}$ Values are means \pm SCM.

${ }^{c} \mathrm{NT}$, not tested.

\section{TABLE ॥}

Effects of ultrafiltration-derived serum fractions on GABAergic neuron survival following a medium change at $7 D N$ in cerebellar primary cultures

The serum was processed through a PM 10 membrane; the retained fractions, $R 10\left(M_{\mathrm{r}}>10,000\right)$, and the filtrate fractions, $F 10\left(M_{\mathrm{r}}<10,000\right)$, were appropriately diluted in BME. Aliquots of the $F 10$ fractions were further processed through a $Y M 2$ membrane, and the corresponding retained $(R$ $\left.2,1,000>M_{r}<10,000\right)$ and filtrate $\left(F 2, M_{r}<1,000\right)$ fractions were diluted in BME. Cultures were grown in serum-supplemented medium until 7 DV and were subjected to a medium change at 2 DIV. At 7 DIV some cultures were subjected to a medium change with the media containing the difterent ultrafiltration-derived serum fractions; parallel cultures, without medium change at 7 DIV, were considered as controls, as in Table I. For the evaluation of GABAergic neuron survival and the expression of the results, see the legend to Table I. Values of GABAergic cell counts are from one duplicate experiment.

\begin{tabular}{lccc}
\hline \multirow{2}{*}{$\begin{array}{c}\text { Serum Fractions in the 7-DIV } \\
\text { Medium Change }\end{array}$} & \multicolumn{3}{c}{ Percentage of Control } \\
\cline { 2 - 4 } & $\begin{array}{c}\left.{ }^{3} \mathrm{H}\right] \mathrm{GABA} \\
\text { Release }\end{array}$ & $\begin{array}{c}\left.{ }^{3} \mathrm{H}\right] \mathrm{GABA} \\
\text { Uptake }\end{array}$ & $\begin{array}{c}\text { GABAergic } \\
\text { Cell Counts }\end{array}$ \\
\hline Control (no medium change) & $100(6)^{a}$ & $100(6)$ & 100 \\
R 10 & $89 \pm 12^{b}(6)$ & $89 \pm 7(5)$ & 96 \\
R $10+\mathrm{F} 10$ & $4 \pm 2(4)$ & $27 \pm 5(4)$ & 7 \\
R $10+\mathrm{R} 2$ & $68 \pm 12(4)$ & $82 \pm 3(4)$ & $\mathrm{NT}^{\mathrm{c}}$ \\
R $10+\mathrm{F} 2$ & $15 \pm 11(4)$ & $37 \pm 8(4)$ & $\mathrm{NT}$ \\
\hline
\end{tabular}

${ }^{a}$ Numbers in parentheses, number of duplicate experiments.

${ }^{b}$ Values are means \pm SEM.

${ }^{c}$ NT, not tested.

process. More direct evidence in favor of this idea was obtained autoradiographically. In fact, depolarization caused a selective depletion of radioactivity in the distal part of the axonal processes of GABAergic neurons, whereas the labeling of astrocytes was not significantly affected (Fig. 5). The inability of cultured astrocytes to release $\left[{ }^{3} \mathrm{H}\right] \mathrm{GABA}$ has been previously demonstrated using confluent astrocyte cultures (Pearce et al., 1981; Schousboe et al., 1983), in which [ ${ }^{3}$ H]GABA uptake is very low (Wilkin et al., 1983).
Our present data show that even the stellate astrocytes, which avidly accumulate $\left[{ }^{3} \mathrm{H}\right] \mathrm{GABA}$ (Levi et al., 1983; Wilkin et al., 1983), do not release the amino acid upon depolarization.

In the second part of the present report we have shown that renewing the culture medium in differentiated neuron-enriched cerebellar cultures (7 DIV) caused a selective and rapid loss of GABAergic neurons but not of granule cells. Loss of GABAergic neurons was documented by counting the number of $\left[{ }^{3} \mathrm{H}\right] \mathrm{GABA}$-labeled neurons or of GAD-positive cells, and by measuring $\left[{ }^{3} \mathrm{H}\right] \mathrm{GABA}$ accumulation and stimulus-coupled release. The agreement between decrease of GABAergic neurons and of $\left[{ }^{3} \mathrm{H}\right] \mathrm{GABA}$-evoked release was excellent. $\left[{ }^{3} \mathrm{H}\right] \mathrm{GABA}$ accumulation was somewhat less affected, probably due to the contribution of astrocytes to the measured [ $\left.{ }^{3} \mathrm{H}\right]$ GABA uptake (Tables I and II). The loss of GABAergic neurons caused by the renewal of the culture medium could be attributed to a diffusible fraction present in the fetal calf serum. All of the GABA-neuronotoxic activity of the serum was lost by ultrafiltration with Amicon PM 10 membranes and most of it was lost by ultrafiltration with YM 2 membranes. Thus, the molccular weight of the toxic factor(s) should be around 1000 or lower.

The observation that serum-containing conditioned media (both neuronal and glial) did not exhibit toxic activity, whereas the GABAneuronotoxic activity was maintained when fresh, serum-containing medium was incubated for several days at $37^{\circ} \mathrm{C}$ in the absence of cells (Table 1), indicates that the toxic factor(s) is inactivated or metabolized by the cells present in the culture, or by cell products secreted into the culture medium. When cultures were grown in the absence of the toxic activity, namely, when they were plated and/ or subjected to a 2.DIV medium change with glial conditioned medium, the number of GABAergic neurons surviving in older cultures was comparable to that of control cultures subjected to a medium change with fresh medium at day 2 ; thus, it appears that at early stages in vitro the GABAergic neurons are not affected either by the presence or by the absence in the culture medium of the toxic activity. It is likely that GABAergic neurons become sensitive to the serum toxic factor(s) only after reaching a fairly advanced degree of differentiation. This is supported by two additional observations: (1) renewal of the culture medium with fresh medium at 5 DIV instead of 7 DIV had only a minimal effect on GABAergic neuron survival (Table I), and (2) a medium change at 7 DIV in cultures obtained from younger animals ( 2 days rather than 8 days postnatal) caused a substantially less pronounced loss of autoradiographically labeled neurons (50\% instead of $90 \%$, unpublished results).

Whereas the number, the organization, and the functional properties $\left(\left[{ }^{3} \mathrm{H}\right]\right.$-D-aspartate uptake and release) of the granule cells did not seem to be significantly affected by a medium renewal at 7 DIV, some loss of [ $\left.{ }^{3} \mathrm{H}\right] \mathrm{GABA}$-labeled astrocytes was observed, although less pronounced and less consistent than that of GABAergic neurons. However, even in the absence of the medium change, the number of astrocytes present in cerebellar neuron-enriched cultures markedly declined during the period of observation, and some of the remaining stellate astrocytes even lost their ability to take up $\left[{ }^{3} \mathrm{H}\right]$ GABA (Levi et al., 1983). The culture conditions used, and in particular the presence of an antimitotic, are certainly not optimal for the survival of astrocytes, and the renewal of the medium at 7 DIV probably causes just an acceleration in their normal death rate.

Recently it has been shown that some serum fractions, with $M_{\mathrm{r}}>$ 35,000 , are toxic to rat central neurons in monolayer cultures (Kaufman and Barrett, 1984); in another investigation, the existence of a serum factor decreasing glucose oxidation by dissociated brain cells was suggested (Tildon and Stevenson, 1984).

To our knowledge this is the first report in which two distinct populations of neurons, the granule cells and the GABAergic interneurons, present in the same culture system (cerebellar primary cultures) are shown to be differentially sensitive to a diffusible fraction of the serum. The low molecular weight fraction which selectively affected the survival of differentiated GABAergic neurons might interact with surface molecules, thus altering cell-cell or cell-substra- 
tum interactions, or might affect the metabolism of GABAergic neurons and cause selective neuronal degeneration. It seems important, therefore, to clarify the mechanism of action of the toxic serum factor(s) and, possibly, the differences in the metabolic and/ or surface properties of the two neuronal cell types.

As a final consideration, through the selective depletion of GA BAergic neurons, one can obtain a 98 to $99 \%$ pure population of granule cells in differentiated cerebellar primary cultures. This unique degree of purity may turn out to be very useful in further studies on the biochemical and antigenic properties of cerebellar granule cells.

\section{References}

Bignami, A., D. Dahl, and D. C. Reuger (1980) Glial fibrillary acidic protein (GFA) in normal neural cells and in pathological conditions. Adv. Cell. Neurobiol. 1: 285-310.

Burry, R. W., and R. S. Lasher (1978) Electron microscopic autoradiography of the uptake of ${ }^{3}$ H.GABA in dispersed cell cultures of rat cerebellums. $I$. morphology of GABAergic synapses. Brain Res. 151: 1-18.

Currie, D. N., and G. R. Dutton (1980) [3/ I]GABA uptake as a marker for cell type in primary cultures of cerebellum and olfactory bulb. Brain Res. 199: 473-481

Eng, L. E., and S. J. De Armond (1982) Immunocytochemical studies of astrocytes in normal development and disease. Adv. Cell. Neurobiol. 3: 145-171.

Farb, D. H., D. K. Berg, and G. D. Fischbach (1979) Uptake and release of $\left({ }^{3} \mathrm{H}\right) \gamma$-aminobutyric acid by embryonic spinal cord neurons in dissociated cell culture. J. Cell Biol. 80: 651-661

Gallo, V., M. T. Ciotti, A. Coletti, F. Aloisi, and G. Levi (1982) Selective release of glutamate from cerebellar granule cells differentiating in culture. Proc. Natl. Acad. Sci. U. S. A. 79: 7919-7923

Garthwaite, J., and R. Balàzs (1981) Separation of cell types from the cerebellum and their properties. Adv. Cell. Neurobiol. 2: 461-489.

Giacobıni, E., A. Vernadakıs, and A. Shahar (1980) lissue Culture in Neurobiology, Raven Press, New York.

Kaufman, L. M., and J. N. Barrett (1984) Serum factor supporting long-term survival of rat central neurons in culture. Science 220: 1394-1396.

Lasher, R. S. (1974) The uptake of $\left[{ }^{3} \mathrm{H}\right] \mathrm{GABA}$ and differentiation of stellate neurons in cultures of dissociated postnatal rat cerebellum. Brain Res. 69 : $482-488$

Levi, G., and M. T. Ciotti (1983) Glutamate and GABA localization and evoked release in cerebellar cells differentiating in culture. In Glutamine, Glutamate and GABA in the Central Nervous System, L. Hertz, E. Kvamme, E. G. McGeer, and A. Schousboe, eds., pp. 493-508, Alan R. Liss Inc., New York.

Levi, G., G. P. Wilkin, M. T. Ciotti, and S. Johnstone (1983) Enrichment of differentiated, stellate astrocytes in cerebellar interneuron cultures as studied by GFAP immunofluorescence and autoradiographic uptake patterns with $\left[{ }^{3} \mathrm{H}\right] \mathrm{D}$-aspartate and $\left[{ }^{3} \mathrm{H}\right] \mathrm{GABA}$. Dev. Brain Res. 10: $227-241$.

Levi, G. F. Aloisi, M. T. Ciotti, and V. Gallo (1984) Autoradiographic localization and depolarization-induced release of acidic amino acids in differentiating cerebellar granule cell cultures. Brain Res. 290: 77-86.

Llinas, R. R., and J. E. Heuser (1977) Depolarization-release coupling syslems in neurons. Neurosci. Res. Program Bull. 15: 557-687.
Messer, A. (1977) The maintenance and identification of mouse cerebellar granule cells in monolayer cultures. Brain Res. 130: 1-12.

Neale, E. A., W. H. Oertel, L. M. Bowers, and V. K. Weise (1983) Glutamate dccarboxylase immunoreactivity and $\gamma-\left[{ }^{3} \mathrm{H}\right]$ aminobutyric acid accumulation within the same neurons in dissociated cell cultures of cerebral cortex J. Neurosci. 3: 376-382.

Panula, P., J. -Y. Wu, and P. Emson (1981) Ultrastruclure of GABA-neurons in cultures of rat neostriatum. Brain Res, 219: 202-207

Pearce, B. R., D. N. Currie, R. Beale, and G. R. Dutton (1981) Potassiumstimulated, calcium-dependent release of $\left[{ }^{3} \mathrm{H}\right] \mathrm{GABA}$ from neuron- and gliaenriched cultures of cells dissociated from rat cerebellum. Brain Res. 206: 485-489.

Pearce, B. R., A. L. Gard, and G. R. Dutton (1983) Tetanus toxin inhibition of $\mathrm{K}^{+}$-stimulated $\left[{ }^{3} \mathrm{H}\right] \mathrm{GABA}$ release from developing cell cultures of the rat cerebellum. J. Neurochem. 40:887-890.

Pfeiffer, S. E., (1982) Neuroscience Approached through Cell Culture, Vol. 1. CRC Press, Inc., Boca Raton, FL.

Reisert, I., G. Jirikowski, C. Pilgrim, and M. L. Tappaz (1983) GABAergic neurons in dissociated cultures of rat hypothalamus, septum and midbrain. Cell Tissue Res. 229: 685-694.

Ribak, C. E. (1978) Aspinous and sparcely-spinous stellate neurons in the visual cortex of rats contain glutamic acid decarboxylase. J. Neurocytol. 7: $461-468$.

Ribak, C. E., J. E. Vaughn, and K. Saito (1978) Immunocytochemical localization of glutamic acid decarboxylase in neuronal somata following colchicine inhibition of axonal transport. Brain Res. 140: 315-332.

Roberts, E. (1979) Now dircctions in GABA research. I. Immunocytochemical studies of GABA neurons. In GABA-Neurotransmitters. Alfred Benzon Symposium 12, P. Krogsgaard-Larsen, J. Scheel-Krüger, and $\mathrm{H}$. Kofod, eds., pp. 28-45, Munksgaard, Copenhagen.

Schousboe, A., O. M. Larsson, J. Drejer, P. Krogsgaard-Larsen, and L. Hertz (1983) Uptake and release processes for glutamine, glutamate and GABA in cultured neurons and astrocytes. In Glutamine, Glutamate and GABA in the Central Nervous System, L. Hertz, E. Kvamme, E. G. McGeer, and A. Schousboe, eds., pp. 297-315, Alan R. Liss Inc., New York.

Snodgrass, S. R., W. F. White, B. Biales, and M. Dichter (1980) Biochemical correlates of GABA function in rat cortical neurons in culture. Brain Res, 190: $123-138$

Tappaz, M. L., M. Aquera, M. F. Belin, W. H. Oertel, D. E. Schmechel, I. J. Kopin, and J. F. Pujol (1981) GABA markers in median eminence. In GABA and Benzodiazepine Receptors, E. Costa, G. Di Chiara, and G. L. Gessa, eds., pp. 229-236, Raven Press, New York.

Thangnipon, W., A. Kingsbury, M. Webb, and R. Balàzs (1983) Observations on rat cerebellar cells in vitro: Influence of substratum, potassium concen tration and relationship between neurons and astrocytes. Dev. Brain. Res. 11: 177-189

Tildon, T. J., and J. H. Stevenson (1984) Decreased oxidation of labeled glucose by dissociated brain cells in the presence of fetal bovine serum. Science 224: 903-904.

Wilkin, G. P., G. Levi, S. R. Johnstonc, and P. N. Riddle (1983) Cerebellar astroglial cells in primary culture: Expression of different morphological appearances and differential ability to take up $\left[{ }^{3} \mathrm{H}\right] \mathrm{D}$-aspartate and $\left[{ }^{3} \mathrm{H}\right]$ GABA. Dev. Brain Res. 10: 265-277.

Wu, J. - Y. (1983) Immunocytochemical identification of GABAergic neurons and pathways. In Glutamine, Glutamate and GABA in the Central Nervous System, L. Hertz, E. Kvamme, E. G. McGeer, and A. Schousboe, eds., pp. 161-176, Alan R. Liss Inc., New York. 